\title{
Implementing a collaborative return-to-work program: Lessons from a qualitative study in a large Canadian healthcare organization
}

\author{
Kathryn Skivington ${ }^{\mathrm{a}, \mathrm{b}, *}$, Marni Lifshen ${ }^{\mathrm{a}}$ and Cameron Mustard ${ }^{\mathrm{a}}$ \\ anstitute for Work \& Health, Toronto, ON, Canada \\ ${ }^{\mathrm{b}}$ MRC/CSO Social and Public Health Sciences Unit, University of Glasgow, Glasgow, Scotland, UK
}

Received 4 April 2015

Accepted 14 January 2016

\begin{abstract}
.
BACKGROUND: Comprehensive workplace return-to-work policies, applied with consistency, can reduce length of time out of work and the risk of long-term disability. This paper reports on the findings from a qualitative study exploring managers' and return-to-work-coordinators' views on the implementation of their organization's new return-to-work program.

OBJECTIVES: To provide practical guidance to organizations in designing and implementing return-to-work programs for their employees.

METHODS: Semi-structured qualitative interviews were undertaken with 20 managers and 10 return-to-work co-ordinators to describe participants' perspectives on the progress of program implementation in the first 18 months of adoption. The study was based in a large healthcare organization in Ontario, Canada. Thematic analysis of the data was conducted.

RESULTS: We identified tensions evident in the early implementation phase of the organization's return-to-work program. These tensions were attributed to uncertainties concerning roles and responsibilities and to circumstances where objectives or principles appeared to be in conflict.

CONCLUSIONS: The implementation of a comprehensive and collaborative return-to-work program is a complex challenge. The findings described in this paper may provide helpful guidance for organizations embarking on the development and implementation of a return-to-work program.
\end{abstract}

Keywords: Return to work, employment, sick leave, organizational innovation

\section{Introduction}

There are substantial financial and social costs associated with sickness absence from work [1]. Healthcare is one sector with high absence rates, because of both work-related and non-work-related causes [2]. Safe and sustainable return to work (RTW) after sickness absence is a challenge, but early RTW is promoted because it encourages recovery and reduces

\footnotetext{
*Address for correspondence: Kathryn Skivington, MRC/CSO Social and Public Health Sciences Unit, University of Glasgow, 200 Renfield Street, Glasgow G2 3QB, UK. Tel.: +44 0141353 7500; E-mail: kathryn.skivington@glasgow.ac.uk.
}

absence time, which makes it less likely that workers will move on to disability benefits, and is therefore associated with lower societal costs as well as lower compensation costs for the employer $[1,3]$.

Extended absence from work is related to more than worker-level characteristics [4]. Workplacelevel factors are also influential, and have been shown to be stronger determinants of the offer and acceptance of workplace accommodation [5]. Workplace accommodation, involving transitional duties or gradual RTW, can reduce duration of absence from work [3]. It is therefore important for organizations to have comprehensive RTW processes. Numerous 
guidelines exist for workplace-based strategies for RTW e.g. Gensby, 2012 [6]; Institute for Work \& Health, 2007 [7]; National Institute of Disability Management and Research (NIDMAR) [8]. Of particular relevance to our study are the role of the return-to-work co-ordinator (RTWC) and the emphasis on labour-management collaboration in the planning of individual RTW plans [8]. These aspects of a new RTW program being implemented in a large organization in Ontario are discussed in depth in this paper, with particular focus on the novel approach of RTWCs as union appointees.

One way the employer can support workers' RTW pathway is to employ a RTWC to assist workers through the process $[3,9]$. Although the presence of a RTWC has been promoted, there is less information available on their specific role, their expertise, and the training they should receive. However, it is thought that it is the coordination itself, and the personal characteristics of the RTWC, rather than the specific background of the coordinator that is important to a smooth and early RTW [3, 10]. RTWCs can be employed in different ways; some are full-time RTWCs employed specifically for this role, and others take it on with only a small proportion of their work time committed to the RTWC role [11, 12].

In developing organizational RTW programs, the roles and interplay of several 'actors' should be considered. For example, internal actors such as the injured worker, their supervisor, co-workers, management, occupational health and safety representatives, human resources, union representatives, as well as external actors who may be involved in RTW in different ways e.g. health professionals, workers' compensation board, lawyers [13-19]. Insufficient or unproductive communication and collaboration between key stakeholders can contribute to longer-than-necessary absence [20, 21]. Qualitative research with different stakeholders of the RTW process, from numerous organizations, has shown that although rare for union representatives to be involved in planning RTW measures, joint commitment and relationships between union and management were perceived to have a large impact on the success of and satisfaction with organizational RTW programs $[15,16]$. However, it remains unclear how such collaborations work in practice.

Guidance exists for best-practice organizational RTW programs, but less is available on the practical aspects of implementing such programs and how this may work in reality, particularly on the novel approach of involving union representatives as
RTWCs. The objective of this paper is to provide an example of the implementation of a RTW program in a large organization, aiming to answer the research question: What were the views of two groups of important workplace actors-managers and return-towork co-ordinators-on the practicality of the newly implemented organizational RTW program? Other perspectives, most notably the workers themselves, are important in exploring RTW programs; however, the perspective of managers and RTWCs has not been as well documented in the literature, and these are key groups who can influence the RTW outcomes of workers [22]. A separate stage of the research will present the viewpoint of the workers involved in the RTW program. We present findings from a qualitative component of an evaluation of the implementation of a novel RTW program in a healthcare employer in Ontario, Canada. Findings from this study may provide guidance to other workplaces that are planning the implementation of a disability management policy.

\subsection{Return to work responsibilities in Ontario}

Employers in Ontario, as in all Canadian provinces, must meet stringent standards to accommodate employees with disabilities. These obligations are established in federal and provincial human rights legislation and have consistently been confirmed by judicial case law [23]. The organization's RTW program was developed in a context where disability income security benefits are provided by two insurance payers. Employers in Ontario are required to obtain insurance coverage for work-related injury and illness from the publicly-administered single-payer workers' compensation agency. Additionally, the employer provides a long-term disability insurance plan for employees who are disabled by non-workrelated conditions.

\subsection{Background to the program}

The RTW program discussed in this study was implemented in the organization in 2012 in an attempt to address the organization's high rates of sickness absence and poor levels of return to work following absence. Prior to its adoption, the organization did not have explicit policies and procedures for supporting those on sickness absence to return to work. The program was aimed at better facilitating RTW after sickness absence, regardless of whether the absence was work-related or not, and at collaboration between 
different stakeholders, particularly union representatives and the employer. It was developed by a steering committee made up of representatives from the employer, relevant unions, and external expertise from supporting organizations (disability prevention and occupational health service to provide consultation on program development). The authors were asked by the organization to be involved as independent evaluators and were therefore not part of the program's development or implementation.

The RTW program has numerous aspects, detailed in Table 1 against previously identified components of disability management programs. It is comprehensive in that it includes all components identified in Gensby et al's (2012) systematic review [8] and in the Institute for Work and Health's 'Seven Principles of RTW' (2007), a report that drew on research to develop important principles for workplace-based RTW systems [7]. Information about the RTW program was disseminated to staff via brochures and by providing information to managers to cascade through their teams. Managers attended a short session on the introduction of the program prior to its implementation.

The distinctive aspect of the organization's program was the recruitment of RTWCs. These individuals were appointed by each of the three unions representing workers in the health system, so that every returning worker would have a representative from their own union as their RTWC. As well as including union representatives in the development and planning phases of the RTW program, this course of action was taken as an innovative way of trying to integrate the involvement of labour and management to work towards the common goal of RTW. In unionized workplace settings, it is common to provide access to union representatives for disabled employees, but having them written into the RTW policy formalizes their role in the process and encourages labour-union collaboration, something that is frequently cited in the disability management literature as being an important aspect of RTW (e.g. $[6,24])$. Some RTWCs have taken on this role as an additional responsibility aside to their main job, with agreed time out of work. Other RTWCs were 'dedicated' to the role in that they have committed most of their time to union work, and the bulk of it is RTW. All remain employees of the organization. RTWCs attended a one-off five-day training course run by external partners, which covered issues related to the program and involved tutorialbased learning as well as practical training e.g. role playing different scenarios. The RTWCs work alongside the organization's Occupational Health and Safety (OHS) Department, who hold overall responsibility for managing the RTW process. All are involved in the RTW meetings, which are held for workers whose return-to-work requires modified duties or modified hours.

\section{Methods}

\subsection{Research design}

The study presented here is one aspect of a larger evaluation of the RTW program where the authors have combined qualitative and quantitative approaches to explore processes and outcomes, taking a pragmatic approach. Here we discuss the findings of the qualitative research that was undertaken to explore how managers and RTWCs viewed the new RTW program in practice. Data were generated through semi-structured interviews, which allowed the interviewer flexibility to explore issues that were raised by the participants. The main objective of the interviews was to facilitate the participants to discuss their own experience of the RTW program. Ethical approval was obtained from the Health Sciences Research Ethics Board, University of Toronto (protocol reference 28503).

\subsection{Recruitment of participants}

An independent contractor at the organization identified all those who took part in a RTW case in 2012 and sent them an email to ask if they consented to having their contact information passed on to our independent research team. Table 2 shows the process of contact. Contact information for managers and RTWCs agreeing to an interview was forwarded to us, and following informed consent, twenty managers and ten union RTWCs were interviewed (Table 3). Through discussion among the research team, it was felt that data saturation was reached, with the managers after around 15 interviews; each were bringing up similar issues and no new themes were evident. At this stage no more managers were recruited but pre-arranged interviews were kept. It was not possible to recruit more than the ten RTWCs. This ten represented each of the three unions and included some RTWCs who were 'dedicated' to the role and others who retained their full time job and worked on RTW cases less frequently. 
Table 1

Alignment of the organization's RTW program to workplace disability management best practice principles

Best practice principles (*) $\quad$ Organization's Return-to-Work (RTW) Program

IWH1: The workplace has a strong commitment to health and safety, which is demonstrated by the behaviours of the workplace parties.

G1.1 RTW policies

G1.2 Active employee participation

G1.3 Joint labour-management commitment

G1.4 Information systems to enhance accountability, on-going monitoring and evaluation
A policy document.

Responsibilities for active involvement of the employee written into the policy.

The program was endorsed by the vice president of human resources, director of labour relations, and union presidents. RTWCs were appointed by union presidents to be involved in each RTW case.

The RTW committee addresses unresolved issues and oversees the program.

IWH2: The employer makes an offer of modified work (accommodation) to injured/ill workers so they can return early and safely to work activities suitable to their abilities.

G2.1 Workplace assessment

G2.2 Provision of workplace accommodation

G2.3 Modified and/or tailored work schedule or duties

RTWCs determine the essential duties of the pre-injury job in conjunction with the employee and manager.

The organization recognises the duty to accommodate the work/workplace to the employee's needs.

Accommodation of the work/workplace may include job modifications, reorganization of work, retraining, provision of technical aids.

G2.4 Transitional work opportunities

Returning employees will be given every reasonable opportunity to work at their own pace.

G2.5 Access to alternative placements

Alternative work will be offered if no accommodation can be made.

IWH3: RTW planners ensure that the plan supports the returning worker without disadvantaging co-workers \& supervisors.

G3.1 Revision of workplace roles

It will not be accepted practice to off-load work from the returning employee to co-workers.

IWH4: Supervisors are trained in work disability prevention and included in RTW planning.

G4.1 Education of workplace staff

The employer, in consultation with the committee, is to ensure development, implementation, and monitoring of the RTW program. It is managers' responsibility that employees participate in RTW training.

G4.2 Preventive strategies to avoid disability re-occurrence

Hazard information, barriers, and accommodation solutions will be systematically shared within the organization.

IWH5: The employer makes an early and considerate contact with injured/ill workers.

G5.1 Early contact and intervention

A letter will be sent to employees within five days of absence to inform them about their RTWC. RTWCs follow up, initially by phone.

IWH6: Someone has the responsibility to coordinate RTW.

G6.1 RTW coordination or case management

Alongside the health practitioner's recommendations, an employer
and a RTWC will work with the employee to determine a RTW
plan. The RTWC is responsible for monitoring progress.

IWH7: Employers and health care providers communicate with each other about the workplace demands as needed.

G7.1 Multidisciplinary work rehabilitation services e.g. vocational The RTWC may utilise internal or external resources to develop and/or clinical (psychological and/or physical) accommodation solutions.

*Workplace disability management best practices: IWH Institute for Work \& Health (7), G Gensby et al. (6).

Although the research may have benefitted from further interviews with RTWCs it was felt that interesting and sufficient themes were arising, which were complimentary to the findings of the interviews with managers, and which could be analysed to provide useful guidance on organizational RTW programs.

\subsection{Data collection}

Two researchers separately conducted semistructured interviews in August-October 2013, when the program had been in place for around 18 months. A topic guide was followed with general themes about the RTW program: responsibilities of key 
Table 2

Number of return-to-work co-ordinators and managers recruited to the study

\begin{tabular}{lll}
\hline Recruitment process & Return-to-work co-ordinators & Managers \\
\hline Took part in a RTW case in 2012 & 29 & 59 \\
Invited to take part & 29 & 57 (2 no longer at the organization) \\
Opted out & 10 & 13 \\
No response & 7 & 17 \\
Interested in taking part & 12 & 27 \\
Interview completed & 10 (2 could not be arranged because of & 20 (after which we felt that we had enough \\
& RTWC's busy work schedules, annual & data from managers and did not arrange \\
& leave etc.) & anymore interviews) \\
\hline
\end{tabular}

Table 3

Participant details

\begin{tabular}{llc}
\hline Managers & & Total $\mathrm{n}(n=20)$ \\
Gender & Male & 5 \\
& Female & 15 \\
Department & Clinical/ward & 13 \\
& Non-clinical & 7 \\
RTWCs & & Total $\mathrm{n}(n=10)$ \\
Gender & Male & 1 \\
& Female & 9 \\
Union affiliation & Union 1 & 2 \\
& Union 2 & 4 \\
\multirow{2}{*}{ Dedicated RTWC } & Union 3 & 4 \\
& Yes & 4 \\
& No & 6 \\
\hline
\end{tabular}

actors; contact with the worker; monitoring the worker's progress; access to information needed to be involved in the RTW process; and an overall assessment of the program. Interviews were flexible to allow for discussion of topics relevant to the participant. Interviews lasted approximately one hour, recordings were transcribed verbatim, and transcripts were checked and de-identified, with pseudonyms assigned.

\subsection{Analysis}

Thematic analysis was conducted by the two researchers who conducted the interviews and constant comparison was made. The authors ensured that the data analysis was rigorous by double coding of the transcripts, and continuous analysis meetings throughout the process, to discuss emerging themes and any differences in coding. Framework was used as an analytical tool for thematic analysis because of certain key features: it aids data management, concepts remain grounded in the data, it allows flexibility, it provides a tool for retaining the original context of each part of data after they have been synthesised, and is systematic [25]. Key themes were discussed and recorded and the data were indexed by theme on to a coding note for each participant. This was an iterative process whereby new themes were added as they arose in the data. Higher-level analysis involved exploring patterns within the thematically-organized data.

\section{Findings}

It was evident in the participants' accounts that there were a number of tensions related to particular aspects of the program. The findings focus largely on the over-arching theme of 'tensions', as analysis of this theme provided the greatest opportunity for learning and providing practical guidance. Participants' views are summarized and organized around the aspects of the implementation of the RTW program that are frequently cited in best-practice guidelines (with reference, where appropriate, to the 7 Principles of RTW detailed in Table 1).

\subsection{Organizational commitment (Principle 1)}

RTWC and management participants were uniformly supportive of the organization's commitment to improve disability management practices and endorsed the adoption of the program. They reported that the organization had a high sickness-absence rate and the effort put into disability management was supported. Some participants, managers in particular, did express the view that the employer had a poor track record of organizational change and had reservations that the implementation of the program would receive sufficient funding and resources to ensure its success. As an example, they noted the OHS department's high caseload combined with the lack of staff in the department, and voiced concern that delays in RTW were inevitable. RTWCs and managers had positive views of the principle of employer and union collaboration embedded in the RTW program, yet also noted the inherent challenges in realizing such collaboration in practice. 


\subsection{Early contact with the worker (Principle 5)}

There was confusion around best practice for initial contact with absent workers. On one hand managers wanted to show their support but on the other they did not want to overstep the mark and be perceived as harassing the worker. For example, Barbara (manager) said "I really have a hard time sometimes knowing if I'm invading somebody's personal space, privacy by phoning or would that make them feel better?" This feeling was commonly reported by managers, who said there was a lack of guidance around appropriate contact with workers off sick. Likewise, RTWCs were critical of some managers who they felt were causing distress to absent workers by calling them before they had returned to work.

\subsection{Return-to-work coordinator role (Principle 6)}

Views on having union representatives as RTWCs were generally positive. However, managers were sometimes frustrated that delays were caused by having to wait for a RTWC to be available for the meeting, particularly when the worker expressed a preference to develop a RTW plan without the participation of a RTWC. Participants spoke of uncertainty about the specific roles and responsibilities of the RTWC. Some expressed the view that the RTWC role had not been fully developed. Barbara (manager) talked about it as being a "flash in the pan" idea-one that had not been followed through. This view was reflected in some of the RTWC interviews, where participants expressed uncertainty of their own role, in particular there was confusion around their title, as they and the managers referred to the OHS staff as the co-ordinators of the RTW program. It was the OHS staff who did the initial organisation and management of each case and who chaired the RTW meetings. It was not clear who was responsible for supporting sustained RTW following the initial RTW phase.

There was discussion about alternate approaches to staffing the RTWC role: whether each union should have a dedicated RTWC working full time on cases rather than relying on a number of RTWCs who would participate periodically. The RTWCs who had other full time jobs in the organization reported that they did not have as much accountability for the returning workers. For example, Bonnie (RTWC) said: "well I figure that if a person has a problem they will come to either me or go to the coordinator [Occupational
Health and Safety] or whatever". RTWCs who participated periodically reported that they did not have the opportunity to build up experience in the role and felt they could not make best use of their training; "if you don't put it into practice right away, you lose a lot" (Jill, RTWC). The 'dedicated' RTWCs were more proactive and seemed to have more knowledge of the process, including the nuances evident in the compensation side of RTW. On the other hand, having a RTWC from the returning worker's department was viewed positively as they were better able to contribute to the RTW plan in "finding the work that stays within his scope" (Tony, manager). Managers and RTWCs had similar views when weighing the advantages and disadvantages of 'dedicated' versus periodical RTWCs.

\subsection{Creating a return-to-work plan (Principles 2 and 3$)$}

Some participants talked about the RTW plans being very generic, "kind of cut and paste, it seems to be kind of the same for everybody in a sense" (Kara, manager), or "cookie-cutter" (Evelyn, $R T W C$ ), rather than being flexible to account for individual differences. Managers reported that some workers did not necessarily need to go through all of the steps in the plan; some could have progressed more quickly than others. Manager and RTWC participants noted a tension between creating RTW plans that are specific to the needs of individual workers yet general enough to be consistent and manageable.

Some participants, in particular but not explicitly RTWCs, noted a disappointment that the focus of discussion during RTW planning meetings tended to be on restrictions rather than on the work participation potential of the worker. Although a focus on "ability" (rather than "restrictions" or "disability") was declared in the RTW program policy document, participants noted that the tools were not in place to facilitate this. For example, the physician's Functional Ability Form (FAF) used in the RTW meeting to help determine RTW, is based on restrictions, not abilities. Also, there were reports from both managers and RTWCs that the FAF assumes that a RTW plan will be progressive, an implicit assumption of a linear recovery, when this is not always the reality. Many people simply "won't fit in that piece of paper" (Jill, $R T W C$ ). There was a clear tension between capturing comprehensive information, the available tools, and the time required to do so, given the workloads of those involved. 


\subsection{Support returning worker without disadvantaging co-workers (Principle 3)}

Most participants said that it would be beneficial for co-workers to be informed of a worker's restrictions during modified duties. Co-workers provided with information about restrictions would then not expect returning workers to do certain duties, would not resent them, or think of them as indolent. Teamwork is required: "you can't live in isolation in healthcare" (Helen, manager), and effective team work requires awareness of issues, such as coworkers' restrictions. Participants noted the conflict between transparency and confidentiality in communicating to co-workers about restrictions. It was said that "there has to be a balance between privacy and what you communicate" ( $\mathrm{Liz}, \mathrm{RTWC}$ ), but there did not seem to be any guidance on how best to deal with this issue, meaning that some managers did not feel it was their place to communicate to co-workers about restrictions. As Jacqui (manager) said: "it is up to the employee to divulge their restrictions. Because truly I can't go and tell somebody what someone's restrictions are because that's a breach of confidentiality."

Participants spoke of the difficulty they had in making sure there is an appropriate accommodation for the returning worker, making sure that the co-workers are not burdened, and that the highest standard of patient care is upheld. In terms of co-workers, if working with someone on modified duties there is the opinion that it makes "the load harder" (Bonnie, $R T W C$ ), whereby co-workers have to "pick up the slack" (Jill, RTWC). Managers also reported this problem, for example, Christine said: modified workers can make it "hard on the people that are having to work around" them. As well as causing irritation and potential for a hostile working environment, participants said that it could lead to a higher risk of injury to co-workers, and have a knock-on effect for patient care.

These concerns were not evident when the modified workers were supernumerary in their department, for example because co-workers generally "love it because now they have a spare pair of hands" (Leah, manager). However this brought up a different challenge: balancing worker/patient safety and budget. The issue of whether workers should RTW as core members of staff or as supernumerary to department requirements provoked much discussion. Although some of the RTWCs did have an appreciation of managers' budgets others were of the opinion that it was the managers' problem to solve and not theirs. This opinion was more evident in departments where the manager-worker relationship was frictional in the first place, or where the workers were disillusioned with their manager's behaviour: "so he cuts the staff on the floor, we work harder, he gets the bonuses. And then he complains about his budget. We don't care about it anymore" (Sam, RTWC). This raised concerns that the incentives given to managers were not conducive to a positive workplace, and did not put managers in position to make the best decisions. However, some RTWCs reported that managers did care about their workers, but that they were in a challenging situation given that their job success was judged in budgetary terms:

"That's generally what the problem is [Okay] budgetary restraints more so than not wanting to follow the labour laws or anything, that's not generally, it's usually money" (Bonnie, RTWC).

Some of the managers reported that the RTWCs, and occasionally the OHS contact, did not appreciate their point of view.

"And it has a budgetary impact that they're not responsible for, but they're driving it, so how do I balance my budget but balance the need for the early RTW plan" (Pat, manager).

There was a tension between duty to accommodate and the budgetary pressures of running a successful organization, further complicated by the need to maintain a high standard of patient care. In interviews it came across that managers generally respected that they had a duty to accommodate and that ultimately the situation was beyond their control. Some reported that the extra budget could be justified because of their obligation "to provide a safe and ethical environment" for workers (Robert, manager). This was particularly apparent if the message of it being a 'safety-first' organization was being filtered down from senior management: "She really pushed safety first, safety first 'we are in a financial crunch but safety first"' (Robert, manager).

\subsection{Independent medical assessment}

An important theme that emerged from the interview data that falls outside of the principles of RTW is that of the Independent Medical Assessment. One aspect of the RTW co-ordination that the union RTWCs did not have control over was that of coordinating the medical assessments, which was done by the OHS department. This highlighted reports of distrust, and there were clear tensions between the RTWCs and the OHS department as a result. 
There was an opinion expressed by some RTWCs that the OHS department would request independent medical assessments of workers because they did not trust or like the results of the assessment provided by the worker's physician. Rather than engage in open communication with the workers' healthcare provider about workplace demands, Independent Medical Assessments were sought. Talking about whether they were justified, Mary (RTWC) said: "No, I don't think so, like I mean if your doctor is saying you can come back to work, you've followed with your doctor for a long time, your doctor knows you better than any other doctor does."

In contrast to the perspective of RTWCs, managers largely welcomed the use of Independent Medical Assessments. While mangers agreed that there were some workers who were not returning to work quickly enough, some offered the interpretation that this was because the workers were abusing their sick time, for example noting "patterns of people that have taken three summers off in a row" (Angela, manager). It is important to note that managers were only talking about a minority of their staff who "take advantage" (Paul, manager); they also talked about workers who were extremely dedicated to their jobs and to RTW. However, the expectation of sick leave was seen by some as being cultivated within the culture of the organization. Therefore, addressing this issue is not necessarily a straightforward task; "bad habits die hard" (Robert, manager).

\subsection{Mental health}

Another theme throughout the interviews that is not specifically aligned to any individual RTW program guideline, but important to discuss here, is the type of health condition or disability that caused the workers' absence from work. Participants reported that it was more difficult to support returning workers with mental health conditions than those with physical health conditions. This was largely because participants reported that they did not feel comfortable dealing with mental ill health, meaning that "no-one's really owning these cases" (Claire, manager). With physical injuries "there are black and white ways of figuring out whether you are better or not" (Christine, manager), it's not so clear-cut for mental health issues "cause if you can't read them, I mean if it's a physical limitation it's easy to fix, if it's an emotional one I find it's a lot harder" (Helen, manager). Also, although not limited to mental health, the unpredictable and episodic nature of mental health also made it difficult; conditions that were prone to flare up were described as a "constant battle" (Leah, manager).

Some RTWC participants said that they did not have the training to make appropriate suggestions for people returning to work with mental health conditions. They also said that other staff had a poor understanding of mental health, and this was substantiated in the interviews. Specific guidance on appropriate accommodations for mental health disability episodes was thought to be missing from the RTW program. For example, the FAF, on which the RTW plan was based, did not provide adequate space for limitations related to mental health; there was a distinct focus on the physical aspects of health.

\subsection{Tensions evident in the RTW program: perspectives and practicalities}

Although there were positive views on the implementation of a collaborative RTW program, there were aspects of it that caused tensions and often left managers and RTWCs unsure of how to progress their RTW cases. These can be split into practicalities about the RTW program that managers and RTWCs were equally frustrated with, and issues related to deeper problems stemming from having multi-perspective involvement, and the trust issues that may go along with this. The following discussion considers what we can learn from these tensions.

\section{Discussion}

Our research has provided insight into the perspectives of two key groups of stakeholders in an occupational RTW program. Although there are other workplace actors, in particular the workers themselves, whose perspective is clearly important, the research provides findings related to implementing a program at the staff level and highlights some issues that could be resolved. The lack of research with these stakeholders, and the importance of their views in the RTW process, has been noted elsewhere [22].

The need to take account of social relations between 'workplace actors' has been identified as a key aspect of improving RTW models and policies [26]. Fostering collaboration between union and employer is particularly challenging given that the nature of their jobs mean that these two groups have different priorities. Trust between union RTWCs and management was not necessarily lacking for all participants, but it was clear that they were viewing the 
situations from their vantage point and rarely taking account of others. The managers saw RTW cases from the perspective of budget, staffing, and patient safety, whereas the RTWCs did not always consider each of these things, or did not view them as their concern. This is not to say that managers were unconcerned about their staff, but that they had numerous conflicting pressures that they had to manage. As other research has shown, managers acknowledged the importance of the union representatives in the process, however sometimes felt that they were unwilling to work towards a compromise, making collaboration problematic [27]. Different perspectives are important because the needs of workers and organizations themselves are not necessarily compatible, and it is unrealistic to expect that all issues between stakeholders will be resolved [20]. However, for collaborative RTW programs to be successful there has to be respectful partnerships. In carrying out the interviews for our study, it was apparent that the process of talking through the issues of the different pressures of each group initiated some of the participants to begin to consider the others' perspective; therefore it is clear that this issue is not insurmountable, but something that needs to be fostered in training.

In one setting, James et al. (2010) reported that RTWCs had a degree of role conflict in that they were an advocate for the disabled worker but were also acting on the employer's behalf [11]. The organization described in the current study adopted a novel approach to improving collaboration-by having union representatives as RTWCs. However, in this setting the RTWC role was not as comprehensive as has been implemented elsewhere [11, 12]. The RTWC role was largely only a 'coordinator' in title; OHS staff did most of the administrative coordination of individual RTW plans. This highlights the importance of monitoring and evaluating change e.g. the introduction of a new RTW program within organizations, to ensure that they are being implemented as planned and can be altered as necessary.

There are pros and cons to having 'dedicated' RTWCs as opposed to RTWCs who fulfil the role alongside their full-time job. Those who have "many hats" may not have the capacity to perform the role as effectively as those who were dedicated RTWCs [11], but on the other hand, those who are chosen purposively to be the RTWC on particular cases may have more expertise in the line of work of the modified worker. This is likely to be organizationspecific, and warrants thought and discussion before implementation.
Follow-up with returning workers is essential for sustained RTW [28]; RTW should not be considered successful at initial RTW [6]. As was the case elsewhere [29], it was clear in our research that nobody assumed formal responsibility for follow up with the returning worker. Continued support, facilitated by monitoring and follow up, is essential, especially when workers find it difficult to cooperate with the RTW process [9]. The findings of this study suggest it is important to specify who has formal responsibility for monitoring the progress of workers in their RTW process, and to ensure that information on progress is shared with the RTW team (manager, OHS, RTWC, worker). Formal processes should be built into the RTW programme to ensure that this happens.

Co-workers are key players in returning workers' experience [17], and there is previous suggestion that they should have a formal role in their colleagues' RTW [30]. Participants were in agreement that it was important for co-workers to know about returning workers' restrictions, but were nervous that sharing this information would breach confidentiality. These findings suggest organizations may find it useful to establish protocols for the content of communications between supervisors and co-workers concerning a RTW plan for a disabled worker.

The organization embraced aspects of the social model of disability when developing the RTW program in that it sought to remove the barriers to RTW that were societal constructions [31]. For example, it encouraged managers to consider how the workplace environment could be modified to allow full participation, rather than solely thinking about the individual's recovery. However, the findings here showed that there was still some focus on a linear trajectory of recovery, e.g. the tools and language used at the RTW meeting, which is not realistic for everyone. In line with recommendations from previous studies, one aim of a RTW program may be to periodically reassess individual RTW goals to ensure that they remain relevant throughout $[4,32]$. These findings suggest organizations may find it useful to establish procedures to monitor the progress of RTW episodes at regular intervals, and in consultation with all stakeholders.

Independent medical assessments were identified as a point of tension among participants in the RTW planning process. Such discourse of distrust and Independent Medical Assessments has been reported in previous research. For example, Lax et al. suggest that although the medical assessment is independent from the patients' usual care, it is not independent from the organisation that contracts out the work i.e. 
the employer, as there is a financial commitment in place [33]. Following from this, previous research has discussed potential negative consequences of Independent Medical Assessments for workers and has questioned their fairness [34]. System redesign has been suggested to retain the independent nature of the assessment, but prevent potential harm to the injured worker. For example, Kilgour et al. suggest numerous changes that are relevant suggestions to counter the issues brought up in this study e.g. a multidisciplinary team approach for assessment; improved communication with injured workers by the workplace about the requirement for the assessment, and by the external assessor about the process of the examination; provision of feedback directly to the injured worker from the assessor to avoid misunderstanding; allowance of subsequent assessments with the same assessor if the injured worker felt that their condition had changed before a final decision had been made; and other measures for the independence and quality of Independent Medical Assessments to be improved [34]. Further evaluative work is required to test the feasibility, acceptability, and effectiveness of such measures.

Long-term absence because of mental health is increasingly common in many countries [35]; there has been a shift in work-related ill health from physical to psychological [36]. However, relatively little is known about RTW programs for those with mental health conditions compared to those with physical conditions, with many programs targeted at those with musculoskeletal disorders [8, 37, 38]. Despite being in a healthcare setting, the study showed that understanding and confidence dealing with mental health was low and that some effort was required to provide general education about mental health in the workplace. Previous research has suggested that employer knowledge, attitudes, and practices around mental health can exacerbate mental health conditions in the workplace [39]. Although there is some positive suggestion of an improvement in employer awareness of common mental health conditions (e.g. from England: [40]), guidance to address work disability due to mental health conditions are difficult to find [41]. There is a substantial need for high-quality research on effective RTW practices in mental health disability episodes.

This manuscript has provided insight into the implementation of a RTW policy that aims to improve RTW rates by fostering union-labour collaboration. This collaboration has been highlighted as important in disability management literature, and our exam- ple has provided practical guidance on development and implementation of RTW policies to foster such collaboration. However, it is still not clear how approaches to improve union-labour collaboration do affect RTW; further research evaluating outcomes is warranted.

\section{Conclusion}

The process evaluation of a RTW program in a large organization has shown that despite adopting a comprehensive program, there remain issues with the integrity and consistency of the implementation of the program. Participants noted a number of strengths in the early stages of the implementation of the RTW program; both managers and union RTWCs acknowledged the organization had achieved a renewed emphasis on quick and smooth RTW, and that administrative procedures had been refined for the internal monitoring of the quality of RTW process and outcomes. However, participants also described circumstances where roles and responsibilities were at times unclear, or where the administration of the RTW program appeared to be inconsistent with the principles of the program. In this study, we have documented the tensions perceived by managers and RTWCs arising from uncertainty or confusion concerning the RTW program. Aligning these tensions to the framework of the seven principles of returnto-work has highlighted the substantial complexity in implementing a comprehensive workplace accommodation program, but has provided some practical guidance for others implementing or updating their organizational RTW policies.

\section{Acknowledgments}

The authors would like to thank the participants who kindly agreed to take part in an interview for this piece of research. Financial support for this research was provided by the Canadian Institutes of Health Research (Grant \#123365). The comments from an anonymous reviewer are also gratefully acknowledged. KS is funded by the UK Medical Research Council (MCUU12017/8 and MCPC13027).

\section{Conflict of interest}

The authors declare that they have no conflicts of interest. 


\section{References}

[1] Loisel P, Anema PR. Handbook of Work Disability: Prevention and Management. New York: Springer Science \& Business Media; 2013.

[2] Nelson A, Fragala G, Mensel N. Myths and facts about back injuries in nursing. Am J Nurs 2003;103:32-40.

[3] Franche RL, Cullen K, Clarke J, Irvin E, Sinclair S, Frank J, et al. Workplace-Based Return-to-Work Interventions: A Systematic Review of the Quantitative Literature. J Occup Rehabil 2005;15(4):607-31.

[4] Young A, Roessler RT, Wasiak R, McPherson K, van Poppel MNM, Anema JR. Developmental Conceptualization of Return to Work. J Occup Rehabil 2005;15(4):557-68.

[5] Franche RL, Severin CN, Hogg-Johnson S, Lee H, Côté $\mathrm{P}$, Krause N. A multivariate analysis of factors associated with early offer and acceptance of a work accommodation following an occupational musculoskeletal injury. J Occup Environ Med 2009;51(8):969-3.

[6] Gensby U, Lund T, Kowalski K, Saidj M, Jørgensen A.K, Filges T, et al. Workplace Disability Management Programs Promoting Return to Work: A Systematic Review. Campbell Systematic Reviews 2012.

[7] Institute for Work \& Health. Seven 'Principles' for Successful Return to Work. Toronto: Institute for Work \& Health 2007.

[8] National Institute of Disability Management and Research. Code of Practice for Disability Management: Describing effective benchmarks for the creation of workplace-based disability management programs. Port Alberni, BC: NIDMAR 2000.

[9] MacEachen E, Clarke J, Franche RL, Irvin E. Workplacebased Return to Work Literature Review Group. Systematic review of the qualitative literature on return to work after injury. Scand J Work Environ Health 2006;32(4):257-69.

[10] Pranksy G, Shaw W, Loisel P, Hong NH, Désorcy B. Development and validation of competencies for Return to Work Coordinators. J Occup Rehabil 2010;20:41-8.

[11] James C, Southgate E, Kable A, Rivett DA, Guest MA, Bohatko-Naismith J. The Return-To-Work Coordinator Role: Qualitative Insights for Nursing. J Occup Rehabil 2011;21:220-7.

[12] Shaw W, Hong Q, Pransky G, Loisel P. A Literature Review Describing the Role of Return-to-Work Coordinators in Trial Programs and Interventions Designed to Prevent Workplace Disability. J Occup Rehabil 2008;18:2-15.

[13] Andersson J, Ahgren B, Bihari Axelsson S, Eriksson A, Axelsson R. Organizational approaches to collaboration in vocational rehabilitation - an international literature review. Int J Integr Care 2011;11:e137.

[14] Auvinen AM, Kohtamäki K, Ilvesmäki A. Workplace health promotion and stakeholder positions: A Finnish case study. Archives Environ Occup Health 2012;67(3):177-84.

[15] Baril R, Clarke J, Friesen M, Stock S, Cole D, The WorkReady group. Management of return-to-work programs for workers with musculoskeletal disorders: A qualitative study in three Canadian provinces. Soc Sci Med 2003;57(11):2101-14.

[16] Frissen MN, Yassi A, Cooper J. Return-to-work: The importance of human interactions and organizational structures. Work 2001;17(1):11-22.

[17] Kosny A, Lifshen M, Pugliese D, Majesky G, Kramer D, Steenstra I, et al. Buddies in Bad Times? The Role of Co-workers After a Work-Related Injury. J Occup Rehabil 2012;23(3):438-49.
[18] Lewchuk W, Robb AL, Walters V. The Effectiveness of Bill 70 and joint health and safety committees in reducing injuries in the workplace: The case of Ontario. Canadian Public Policy 1996;(22):225-43.

[19] Loisel P, Durand MJ, Baril R, Gervais J, Falardeau M. Interorganizational collaboration in occupational rehabilitation: Perceptions of an interdisciplinary rehabilitation team. J Occup Rehabil 2005;15(4):581-90.

[20] Franche RL, Bari R, Shaw W, Nicholas M, Loisel P. Workplace-Based Return-to-Work Interventions: Optimizing the Role of Stakeholders in Implementation and Research. J Occup Rehabil 2005;15(4):525-42.

[21] MacEachen E, Kosny A, Ferrier S, Chambers L. The Toxic Dose of System Problems: Why Some Injured Workers Don't Return to Work as Expected. J Occup Rehabil 2010;20:349-66.

[22] Maiwald K, Meershoek A, De Rijk A, Nijhuis FJ. Policy on manager involvement in work re-integration: Managers' experiences in a Canadian setting. Work 2013;49(3):483-94.

[23] Ontario Human Rights Commission. Policy and guidelines on disability and the duty to accommodate. Ontario 2009. Available from: http://www.ohrc.on.ca/en/policy-andguidelines-disability-and-duty-accommodate (accessed October 2015).

[24] Westmorland MG, Buys N. A comparison of disability management practices in Australian and Canadian workplaces. Work 2003;23(1):31-41.

[25] Spencer L, Ritchie J, O'Connor W. Analysis: Practices, principles and processes. In: Ritchie J, Lewis J, editors. Qualitative research practice A guide for social science students and researchers. London: Sage Publications Ltd; 2003. p. 199-218.

[26] Tjulin A, Maceachen E, Edvardsson Stiwne E, Ekberg K. The social interaction of return to work explored from co-workers experiences. Disabil and Rehabil 2011;33(2122):1979-89.

[27] Williams-Whitt K. Impediments to disability accommodation. Industrial Relations 2007;62(3):405-32.

[28] Butler RJ, Johnson WG, Baldwin M. Managing work disability: Why first return to work is not a measure of success. Industrial and Labor Relations Review 1995;48(3): 452-69.

[29] Tjulin A, MacEachen E, Ekberg K. Exploring Workplace Actors Experiences of the Social Organization of Returnto-Work. J Occup Rehabil 2010;(20):311-21.

[30] Dunstan DA, MacEachen E. Bearing the brunt: Co-workers' experiences of work reintegration processes. J Occup Rehabil 2013;23(1):44-54.

[31] Oliver M. The Politics of Disablement: A Sociological Approach. New York: St. Martin's Press; 1990.

[32] Wells M, Williams B, Firnigl D, Lang H, Coyle J, Kroll T, et al. Supporting 'work-related goals' rather than 'return to work' after cancer? A systematic review and meta-synthesis of 25 qualitative studies. Psychooncology 2013(22):120819.

[33] Lax MB, Manetti FA, Klein RA. Medical evaluation of work-related illness: Evaluations by a treating occupational medicine specialist and by independent medical examiners compared. Int J Occup Environ Health 2004;10(1):1-12.

[34] Kilgour E, Kosny A, Akkermans A, Collie A. Procedural Justice and the Use of Independent Medical Evaluations in Workers' Compensation. Psychol Inj and Law 2015;8:15368.

[35] Organisation for Economic Co-operation and Development. Sickness, disability and work: Breaking the barriers. A 
synthesis of findings across OECD countries. Paris: OECD 2010.

[36] Carder M, McNamee R, Turner S, Hodgson JT, Holland F, Agius RM. Time trends in the incidence of work-related mental ill-health and musculoskeletal disorders in the UK. Occup and Environ Med 2013;(70):317-24.

[37] Gallie KA, Shultz IZ, Winter A. Company-level interventions in mental health. In: Shultz IZ, Rogers ES, editors. Work Accommodation and Retention in Mental Health. New York: Springer Science; 2010.

[38] van Oostrom SH, Driessen MT, de Vet HCW, Franche RL, Schonstein E, Loisel P, et al. Workplace interventions for preventing work disability. Cochrane Database of Systematic Reviews 2009;2:Art. No.: CD006955.
[39] MacAulay, A. An examination of mental illness in Canadian workplaces: A content analysis of trends and directions in Canadian arbitration case decisions. University of Prince Edward Island, Charlottetown, P.E.I. 2010.

[40] Henderson C, Williams P, Little K, Thornicroft G. Mental health problems in the workplace: Changes in employers' knowledge, attitudes and practices in England 2006-2010. The British Journal of Psychiatry 2013;202:s70-s76.

[41] Joosen MCW, Brouwers EPM, van Beurden KM, Terluin B, Ruotsalainen JH, Woo J-M, et al. An international comparison of occupational health guidelines for the management of mental disorders and stress-related psychological symptoms. Occupational and Environmental Medicine 2015;72(5):313-22. 